\title{
RECENSIONES / REVIEWS
}

La estética musical de Wagner desde Beethoven. Wagner, R., Beethoven, Madrid, Caligrama, 2021, 156 pp. Traducción, estudio introductorio y notas de Montserrat Armas Concepción

2020 iba a ser, en el calendario musical, un año señalado con grandes carteles de neón. Se cumplían 250 años del nacimiento del compositor más aclamado en la longeva historia de este arte: L. v. Beethoven. Este debía haber sido un año en el que su protagonismo se hubiese hecho notar aún más, no solo sobre el escenario y en los programas de conciertos (festivales que se vieron truncados y retrasados por la pandemia que ha asolado y azotado nuestro modo de vida), sino también desde las publicaciones de las distintas editoriales. Muchos han sido los escritos que recientemente han ido tras sus huellas, por ejemplo, la reedición de Adorno, Th.: Beethoven. Filosofía de la música, Sonneck, O.G.: Beethoven contado a través de sus contemporáneos, e incluso obras con un carácter marcadamente juvenil como Beethoven: un músico sobre un mar de nubes.

Es más, esta misma obra que Richard Wagner escribió como celebración del centenario de Beethoven ha atraído especialmente a los analistas y traductores. Varios han sido los que se han acercado al Beethoven del lipsiense para llevar sus palabras al público hispano. La primera de estas traducciones fue la realizada de mano de Blas Matamoro en 2016, momento en el que aún se sentían los últimos coletazos del bicentenario del nacimiento de Wagner, acaecido en 2013, y ya se preludiaba lo que iba a suceder cuatro ańos después con el de Beethoven. Otra traducción más cercana a la famosa efeméride es la editada por Casimiro. Está claro que estos dos aniversarios tan señalados han hecho que este doble acercamiento a las figuras de Beethoven y Wagner haya sido casi una necesidad sentida desde lo más profundo de las entrañas de la cultura occidental.

Centrándonos en esta nueva traducción realizada para Caligrama, contemplamos una edición visualmente correcta, con una letra amplia, tamaño manejable y unas notas comentando o aclarando cuestiones del texto que resultan útiles. Por otro lado, llama la atención el perfil de la autora: Montserrat Armas, doctora en Filosofía por la Universidad de La Laguna. Sobresalen sus intereses y líneas de investigación, al estar desarrolladas en torno a los dos filósofos más cercanos a Wagner: Friedrich Nietzsche y Arthur Schopenhauer. Intelectuales, además, cuyos pensamientos le otorgaron a la música la capacidad de llevar a cabo un proyecto filosófico. Con tal currículo, la autora demuestra poseer ampliamente la experiencia heurística y hermenéutica necesaria para afrontar un texto de tal índole, en el que la interacción entre la música y la filosofía desdibuja los límites entre sí. Esta indefinición entre ambas disciplinas hace que este escrito salido del puño y letra de Wagner se haya convertido en una joya que interese tanto a melómanos y musicólogos, así como a adeptos de la filosofía.

Su bagaje filosófico se palpa muy de cerca en el estudio introductorio con el que presenta este breve texto wagneriano. Durante las 40 páginas que completan su análisis, al que tituló «El poder regenerador de la música», Armas analiza el trasfondo filosófico de este ensayo. Para conseguir tal fin, a lo largo de los cinco capítulos en que subdividió su estudio, pasa revista sobre los grandes protagonistas de esta historia y su relación con la generación de este escrito. Ello hace que su estudio vaya más allá de asuntos históricos referidos al convulso periodo de la historia que le tocó vivir al compositor (últimos coletazos de la belicosa unificación alemana), y del mero 
dato anecdótico y erudito, como las simpatías e iras que suscitaba entre sus contemporáneos, el éxito o fracaso inicial de alguna de sus obras, su agitada vida íntima, viajes, etc. Al contrario, tal y como indica la propia autora, ella pretende poner en contacto a Schopenhauer, a Wagner y a Nietzsche a partir del Beethoven, para recorrer las vías de doble sentido que dibujan la interacción entre todos ellos. Para realizar esto, en cada uno de los capítulos, Armas relaciona a Wagner con uno de esos protagonistas, desarrollando los distintos puntos de unión. Con tal proceder, ella pretende situar al lector en un lugar privilegiado donde poder observar de cerca la estética musical del compositor, además de su proclama de una autonomía del arte.

En el primero de los capítulos de su estudio introductorio, expone la importancia de este escrito para poder conocer al Wagner teórico. Presenta su Beethoven como un texto imprescindible a la hora de intentar aprehender su faceta teórica, pues, junto con Ópera y drama, contiene las aportaciones más significativas a su estética musical, llegando a construir toda una teoría del acto poético, y marcando su último periodo de reflexión filosófica.

El segundo capítulo lo destina a analizar la relación de Wagner con el protagonista principal de su escrito: Beethoven, a quien veía como su maestro, guía y mentor. La autora no yerra al mostrar la importancia de este para Wagner. De hecho, además de todos los datos que da, podríamos remitirnos a los ańos discurridos alrededor de 1840, momento en que le dedicó un tiempo y unas fuerzas inusitadas a trabajar en una biografía sobre él, y proyectada para que fuera realizada en dos volúmenes. Este esfuerzo, que definitivamente quedó no nato, fue realizado junto con un bibliotecario nacido en Bonn pero radicado en París: Gottfried Engelbert Anders.

En el tercer capítulo, disecciona la relación de Wagner con Schopenhauer, sacando a relucir la clara influencia y filiación que posee este ensayo con la obra principal del francfortés, $E l$ mundo como voluntad y representación. Es en este punto cuando entran en acción las profundas lecturas que el compositor practicó de la obra del filósofo, y que en este ensayo dedicado a Beethoven son desparramadas sobre las duras vivencias y desprecios que sintió durante su aventura en París. Armas, por ejemplo, relaciona la teoría de los tipos de hombres establecida por Schopenhauer (mundano, genio y santo) con ese exacerbado nacionalismo que Wagner saca a pasear, al contraponer el alma francesa y la alemana. La primera sería la que se siente llena y satisfecha, y es zarandeada por las pasiones. En cambio, la segunda, personalizada perfectamente por Beethoven, y al no estar interesada por lo mundano y fenoménico, es capaz de abandonar el mundo ordinario y de acceder al fondo de las cosas. Los genios se convierten así en sujetos puros del conocimiento.

Otro factor importante de la relación intelectual entre Wagner y Schopenhauer que reluce en su Beethoven es el cambio de actitud frente a la música respecto de las demás artes. Y es que el influjo del filósofo ${ }^{1}$ sobre él fue tal que le obligó a replantearse los ambages doctrinales plasmados en sus anteriores ensayos, donde proclamaba una obra de arte total (Gesamtkunswerk) en la que se integraban y fusionaban las seis artes (música, danza, poesía, pintura, escultura y arquitectura), a diferencia de lo que denunciaba que sucedía en el tipo de ópera imperante en su época, a la que acusaba de centrarse demasiado en argumentos fatuos con música casi subordinada a requerimientos del texto y lucimiento de los solistas que dejaban casi ignorados a los demás elementos. Es por ello por lo que, con el ojo puesto en esa obra de arte total, Wagner le concediera la importancia que le otorgó a elementos ambientales, como la iluminación, efectos de sonido, la disposición de los asientos, etc. Todo ello para centrar la atención del espectador en lo que estaba ocurriendo sobre el escenario, y lograr con ello su completa y profunda inmersión en el drama. En cambio, en este ensayo sobre Beethoven propone que, aunque todas las formas de arte tengan gran importancia, no todas son necesariamente igual de importantes. Así, inspirado

\footnotetext{
1 Para Schopenhauer, la música, a diferencia de las otras artes, era capaz por sí sola-nulla imitatio-de representar la voluntad misma del hombre. La música es una creación inconsciente, una inspiración lejos de toda reflexión emparentada con el concepto.
} 
por el pensamiento de Schopenhauer, rompe con aquel equilibrio interartístico e intenta imponer la 'supremacía' de la música, que ahora para él es lo que define a una obra. Esto lo lleva a cabo mediante una compelida dialéctica que culmina con el enaltecimiento de la melodía alemana y de la ínclita figura de Beethoven.

Asimismo, también es reseñable que todo ese cambio intelectual que floreció en Wagner a raíz de sus lecturas schopenhauerianas revirtió en su práctica compositiva, en una clara ejemplificación de la importancia de una existencia de interconexión y dialéctica entre teoría y praxis. Así, en sus dramas maduros, como Tristán e Isolda, La valquiria, Sigfrido, El ocaso de los dioses y Parsifal, va ganando de manera creciente mayor importancia el contenido musical.

El cuarto capítulo lo dedica Armas a la compleja relación que se creó en torno a las personalidades de Wagner y Nietzsche. Esta amistad comenzó en 1868, momento en el que ocurrió el primer encuentro personal entre ambos. Un año después, Nietzsche fue nombrado profesor en Basilea, lo que estrechó aún más los lazos con el compositor, pues fue asiduamente invitado a su casa de Tribschen, en Lucerna, introduciéndolo consecuentemente en su círculo más íntimo.

El impacto de tal amistad en un joven Nietzsche fue profundo, y en poco tiempo vio al compositor como un visionario del mundo (Weltanschauunger) comparable a Schopenhauer, a quien él también admiraba. Concretamente, la relación de Nietzsche con el Beethoven de Wagner fue temprana y profunda. Tal y como bien relata Armas, ya el 29 de julio de 1870 escuchó lecturas realizadas por Wagner en su casa de Tribschen, en noviembre recibió un ejemplar manuscrito y por navidad ya uno lujosamente impreso. Él sintió este ensayo como un reto lanzado por el maestro, al que respondió con su obra El nacimiento de la tragedia, donde hay ideas centrales incluidas ya en el ensayo Beethoven. Nietzsche se dejó influir por este breve ensayo, y muchas de las ideas centrales de su primera obra estaban ya explícitas o insinuadas en él. Una de ellas, por ejemplo, es la necesidad de que se dé una renovación en la cultura alemana, la cual ha perdido los verdaderos referentes, por lo que le urge una mirada al pasado, acción que debe llevar a cabo el genio. Es él quien debe crear las condiciones necesarias para que surja en Alemania una cultura trágica. El quinto capítulo continúa con el empuje de esa relación que floreció entre Nietzsche y Wagner, al menos en los primeros años, pues Armas no se prodiga fuera del momento en que tal amistad estaba en su punto más álgido. Pero es lógico que no haya ido más allá, pues lo que la autora pretende es mostrar el nexo entre Wagner y Nietzsche a través de este ensayo destinado a la figura de Beethoven. Concretamente, en este episodio expone el sacrificio teórico-intelectual que Nietzsche le ofreció al compositor, y las consecuencias que este tuvo para su vida académica.

Tras culminar su estudio introductorio, Armas presenta la bibliografía empleada para su realización. Esta recoge 59 libros, pero para ser un trabajo cuyos protagonistas son Wagner y Beethoven, el peso de la misma (25 libros, y no contando los del tándem Wagner-Nietzsche) recae sobre todo en la figura de Nietzsche. Por el contrario, en ella la imagen de Schopenhauer y Beethoven es casi anecdótica frente a la del de Röcken.

Otro aspecto que resulta llamativo en la bibliografía es la ausencia de alguna historia general de la música, pero sin embargo sí se empleó el primer volumen de Historia de la filosofía griega de Guthrie. Esto da a pensar que, quizás, no se ha sopesado el delicado equilibrio entre música y filosofía que requiere una obra como la presente. Algo de lo que también adoleció en ciertos momentos el propio Wagner, pues si nos dirigimos a su texto, este, aunque sea un ensayo que se titula Beethoven, y que estaba destinado al centenario de su nacimiento, tiene como tema principal una estética musical en la que todo está explicado con un cariz político. Beethoven, de quien no empieza a comentar recurrentemente tras pasadas veintiséis páginas, parece ser una excusa o un tema secundario o concreción y ejemplificación de las afirmaciones que quería terminar comprobando: la superioridad del espíritu alemán, paladín frente a la corrupción que representaba el vanagloriado y pavonador espíritu francés.

Wagner inició su ensayo con un breve prólogo de dos páginas, en el que presenta cuáles 
fueron los planes iniciales para la celebración de un evento tan importante en el mundo de la música, y los beneficios que obtuvo el formato definitivo en el que se realizó: el ensayo, lo que le obligó a ser más concienzudo y sistemático en su desarrollo y conclusiones.

Como se dijo más arriba, en ciertos momentos Beethoven queda «oculto» entre las líneas de la angulosa ( $\mathrm{y}$ a menudo poco fluida) y punzante prosa wagneriana. Wagner, en este ensayo, casi que estuvo más preocupado en presentar y construir una teoría de la música que en realizar un estudio crítico-interpretativo de Beethoven. Partiendo del pensamiento de Schopenhauer, presentó la música como la experiencia que nos fusiona con la totalidad de la naturaleza, acercándonos al infinito. Esta nos colma y excita en nosotros el éxtasis de la consciencia de lo ilimitado, algo que es imposible de traducir a concepto. $\mathrm{He}$ ahí lo que distingue a la música y la eleva sobre el resto de las artes: es una idea del mundo en la que este manifiesta inmediatamente su esencia.

Pero todo esto no tiene que llevar a equívocos, cuando Wagner habla de Beethoven lo hace desde una perspectiva completamente elogiadora y desde el más absoluto respeto, haciéndole poseedor de un carácter rebelde que le permitió resistirse a las modas del momento, que buscaban lo agradable. Afirma de él que se dirigió hacia lo profundo, la esencia del mundo, expresando la más insondable sabiduría en un lenguaje que su razón no comprende, el lenguaje más puro que existe según Schopenhauer y Wagner: la música. Cuando habla de él lo hace para que este se constituya como el recipiente de las afirmaciones del filósofo en torno a la música y al genio creador.

Por último, un documento interesante que ofrece esta edición es la traducción, a modo de apéndice, de un final alternativo y más polémico que Wagner escribió posteriormente, pero que quedó inédito. Son tres incendiarias páginas en las que vuelve a enaltecer al espíritu del pueblo alemán y sus hazañas, a las que conduce el son $\mathrm{y}$ ritmo del gran Beethoven.

Saturnino Expósito Reyes

Uiversidad de La Laguna

DOI: https://doi.org/10.25145/j.laguna.2021.49.09 